\title{
Partial ownership of local firms and zoning of neighboring towns
}

\author{
Juan Carlos Bárcena-Ruiz*. F. Javier Casado-Izaga ${ }^{\dagger}$
}

March 27, 2019

\begin{abstract}
This paper investigates zoning in two neighboring towns in which firms are owned by investors that reside in the two towns. We find that local regulators use zoning strategically depending on the weight of local profits in social welfare. When they are high enough both towns are zoned. For intermediate values an asymmetric result emerges: only one regulator resorts to zoning despite the symmetry in the percentage of ownership of the neighboring firms. For a low weight of local profits, towns may or may not be zoned. Zoning restrictions on the location of firms are tighter when local profits are more significant for social welfare.
\end{abstract}

JEL Classification: L13 . R32 . R38.

Keywords: Zoning . spatial competition . foreign ownership . location choice.

\footnotetext{
*Departamento de Fundamentos del Análisis Económico I. Universidad del País Vasco, UPV/EHU. Av. Lehendakari Agirre 83, 48015, Bilbao, Spain. (e-mail: juancarlos.barcena@ehu.es)

†Departamento de Fundamentos del Análisis Económico I. Universidad del País Vasco, UPV/EHU. Av. Lehendakari Agirre 83, 48015, Bilbao, Spain. (e-mail: franciscojavier.casado@ehu.es)
} 


\section{Introduction}

In cities all around the world zoning regulations set the uses to which land in a municipality may be put, e.g. residential, commercial, light or heavy industrial, recreational, and farming. Zoning design is concerned, among other issues, with the health and safety of residents and with so called "fiscal zoning". 1 Due to negative externalities for the population of towns, heavy industry and some commercial activities are kept apart from residential and educational areas. However, light industry and commercial activities with few or no negative externalities may share space with some residential areas.

This paper focuses on a subject that, to the best of our knowledge, has received little attention from the literature on zoning: How partial ownership of local and neighboring firms affects the optimal zoning design of a municipality when zoning is used strategically.

Literature on zoning has applied location models to analyze the effect of zoning city lands on firms' profits, consumer surplus, consumers' transportation costs, and social welfare. ${ }^{2}$ For example, Lai and Tsai (2004) study asymmetric zoning: The left-hand part of a linear city is exclusively residential. Their zoning proposal may reduce distortion in the total transportation costs of consumers and enhance social welfare. Chen and Lai (2008) study symmetric central zoning under spatial Cournot competition and show that zoning regulation can improve social welfare. Colombo (2012) analyzes a spatial non-discriminatory Cournot duopoly with a central zoning area that may be asymmetric. Finally, Bárcena-

\footnotetext{
${ }^{1}$ From the viewpoint of "fiscal zoning" local authorities may try to keep out relatively lowincome residents for example by increasing the size of the minimum lot for building a singlefamily house or by reducing the number of apartments that can be built. A related branch of the literature on spatial models analyzes tax competition among perfectly competitive firms within local jurisdictions in metropolitan areas located on a line (see, for example, Braid 1993, 2000).

2 The seminal work in analyzing the location of competing firms in linear cities is Hotelling (1929): Two firms simultaneously locate within a linear city and then simultaneously decide their prices. He assumes that consumers' transportation costs are linear, which implies that there is no price equilibrium when firms locate close enough (see d'Aspremont et al. 1979). However, d'Aspremont et al. (1979) show that under quadratic transportation costs the game has a price equilibrium for all locations of the firms.
} 
Ruiz et al. (2016) study an unconstrained duopoly where firms set mill prices. A regulator biased towards consumers allows the two firms to locate in a central area of the city while a regulator highly concerned about firms restricts them to locations outside the city boundaries. ${ }^{3}$

The papers cited above analyze the zoning design of a single city but they do not study zoning of neighboring towns. Empirical evidence highlights the need to analyze the strategic interaction between local governments in neighboring towns. Evidence of the strategic use of zoning is found in towns located in the same country. Henninger (2015) states that regional shopping centers attract residents and sales tax revenue from neighboring cities. ${ }^{4}$ Municipalities are widely observed to encourage the location of shopping centers near or well connected with their borders to attract foreign consumers. There is evidence of Norwegians going shopping to Sweden (Lorentzon 2011; Löfgren 2008). Similar evidence is found on the Dutch-German border (Spierings and van der Velde 2013), on the frontier between Mexico and the US (Sullivan et al. 2012), and on that between Canada and the US (Timothy and Butler 2005).

Towns are run by city councils which are concerned with local welfare, so they may use zoning to push domestic firms, which have to observe urban planning regulations, into locating in specific zones of the town. This may increase local welfare, e.g. due to direct and indirect local employment, local tax collection, and spending by shoppers on travel and meals. As a result, the use of zoning in neighboring towns may have a strategic purpose. With regard to this issue, Bárcena-Ruiz and Casado-Izaga $(2017,2018)$ analyze the use of zoning as a strategic device for capturing economic rents from neighboring consumers

\footnotetext{
${ }^{3}$ Bárcena-Ruiz and Casado-Izaga (2014) also analyze optimal zoning when two firms can price discriminate between consumers. Bárcena-Ruiz et al. (2014) study optimal zoning in a mixed duopoly framework. Matsumura and Matsushima (2012) show that restricting the locations of firms to the linear city reduces consumer welfare when firms sign strategic reward contracts with their managers. Hamoudi and Risueño (2012) study zoning in a circular city where firms and consumers are located on different sides. Suzuki (2013) analyzes the anticompetitive effect of land use regulations, since zoning may discourage entry.

${ }^{4}$ Examples of strategic behavior by local authorities can be found in the US and in Europe (see Hanssen and Foslt 1998; Boarnet and Crane 1988; Heim 2012; Hrelja et al. 2012).
} 
and preserving local rents. Bárcena-Ruiz and Casado-Izaga (2018) study the use of zoning as a strategic device by the regulators of two adjacent towns that form a linear city. Each town is composed of a residential area and its surroundings, which have no residential use but where firms may locate. They consider that zoning costs are meaningful and show that both regulators zone their towns when the fixed zoning cost is low enough and decline to zone when it is very high. ${ }^{5}$ The two symmetric equilibria coexist when the zoning costs take intermediate values. Bárcena-Ruiz and Casado-Izaga (2017) study the regulators' incentives to zone two adjacent towns when firms can only locate in the residential area. In this setting, an equilibrium in which only one regulator zones its town emerges for intermediate values of the fixed zoning cost. The zoning regulations forbid the local firm to locate very far from the consumers of the neighboring town. ${ }^{6}$ However, this literature has not considered how the nationality of the owners of the firms affects zoning decisions by regulators.

Literature on zoning mainly considers competition between domestic firms. However, in economic literature it is well known that the nationality of firms plays a crucial role. ${ }^{7}$ The partial ownership of a local firm by foreign investors may condition the regulators' incentives to zone their towns and the optimal design of zoning. Cato and Matsumura (2017) show other models in which "whether the private firm is domestic or foreign often yields contrasting results in the literature on mixed oligopolies. See Corneo and Jeanne (1994), Fjell and

\footnotetext{
${ }^{5}$ Bárcena-Ruiz and Casado-Izaga (2017) point out that zoning costs are meaningful because "there are costs linked to studying regulation, to designing the maps that plot the different uses of different areas in the town, to uploading those maps and regulations to the web site that offers the information; and there are costs for the staff who inform about and watch for non-fulfillment of the norms, to mention just a few."

${ }^{6}$ Inoue et al. (2009) study the location of a public firm and a private firm in a city with two symmetric districts, each of which is run by a local government. However, they do not study zoning decisions.

${ }^{7}$ For example, Bárcena-Ruiz and Casado-Izaga (2016) show that the nationality of firms influences the design of the optimal zoning by a regulator in a duopoly model of spatial price discrimination. Matsushima and Matsumura (2006) analyze the spatial location of firms in a mixed oligopoly when there are foreign private firms, and Matsumura et al. (2009) investigate whether or not privatization is beneficial from the viewpoint of social welfare in a monopolistic competition model.
} 
Pal (1996), Pal and White (1998), Bárcena-Ruiz and Garzón (2005a, 2005b), Heywood and Ye (2009), and Lin and Matsumura (2012)." In our model, welfare comprises the surplus of domestic consumers and the profits obtained by local investors in both towns. As a result, who owns the competing firms is a relevant issue to keep in mind when designing optimal zoning.

There is empirical evidence of foreign ownership of firms located in neighboring towns or countries. A 2003 reseach report called Foreign Investment: U.S. Border Towns, ${ }^{8}$ points out that "Since the creation of NAFTA, cities located along the northern and southern borders of the United States have developed relationships with sister cities in Canada and Mexico, making free-trade across the border even easier." It also argues that "NAFTA, which has created a powerful free-trade zone among the U.S., Canada, and Mexico, has led to the establishment of some "sister-city" relationships along the borders." With regard to foreign investment the report states that "Much of this foreign direct investment is concentrated in our neighbors to the north and south, Canada and Mexico." Salcedo (2003) provides further evidence and points out that the structure of ownership of malls differs from one country to another. For example, malls in Eastern Europe are completely foreign-owned (partly by western European investors) but malls of the middle East are mainly domestically-owned. In Argentina investment came from a neighboring country: Chile. Chilean mall developers are also active in other countries of South America. ${ }^{9}$

This paper considers a linear city composed of two adjacent towns whose land is for residential use. Each town has a regulator which maximizes local welfare, which comprises the local consumer surplus and the profits obtained by local investors. We assume that in each town a percentage $\alpha$ of the local firm is owned by local investors and the rest is owned by investors from the neighboring

\footnotetext{
${ }^{8}$ Available at: http://www.bastianpr.com/wp-content/uploads/2014/07/Foreigninvestment_-U.S.pdf

${ }^{9}$ In Europe, French real estate investment trust Klépierre has recently acquired shopping malls in Spain and the Netherlands and owns shopping centers in 57 cities in 16 countries (http://www.klepierre.com/en/who-we-are/in-brief/).
} 
town. Local authorities are able to regulate the location of the firms within their towns, but prices are freely decided by the two firms. To maintain a structure of analysis close to the duopoly models analyzed in the seminal papers, we consider that only one firm operates in each town, though they can sell their products in both markets. Each regulator decides whether to zone its town or not, and zoning does not entail a fixed cost. In each town zoning may be used to achieve the optimal location of the local firm by limiting some urban area to residential use only. We consider that zoning defines two different areas: an area in which firms and consumers may share the same locations (both commercial and residential uses) and an exclusively residential area.

Our results show that the incentives to zone one town, and the zoning constraints when applied, crucially depend on the percentage of the local firm owned by local investors. When it is high enough both regulators zone their towns to push the local firm towards the frontier with the other market in order to gain some foreign consumers and to reduce local consumers' transportation costs. So zoning constraints forbid the local firm to locate very far from its rival. For intermediate values of the percentage of the local firm owned by local residents an asymmetric result emerges. In this case only one regulator resorts to zoning despite the symmetry in the percentage of ownership of the neighboring firms. This asymmetric result has been obtained before in the literature in a model of the same nature when only local profits matter, under the assumption that fixed zoning costs are meaningful (Bárcena-Ruiz and Casado-Izaga, 2017). In this paper we do not consider fixed zoning costs, so the asymmetric result arises because foreign profits are significant. Thus, it may not be attractive to zone the town when the rival does so, because then intense competition erodes the profits obtained by the firm from the other town. This plays an important role when the equilibrium involves zoning in one town only and the regulator which does not zone its town obtains higher social welfare than the other because foreign profits are substantial in comparison to local profits. Finally, for a low 
enough weight of local profits all possible equilibrium configurations, applying zoning or declining to zone in each town, are possible because the objectives of the regulator and the firms are not in conflict.

The rest of the paper is organized as follows. Section 2 presents the model. Section 3 studies the regulators' incentives to zone their towns or not, and Section 4 draws conclusions.

\section{The model}

Consumers are distributed uniformly and with unitary density along a linear city, the interval $[0,1]$, that comprises two adjacent towns of the same size. The town to the left, denoted as town 1 , extends along the interval $[0,1 / 2]$, while the town to the right (town 2) extends along the interval $[1 / 2,1]$. Each consumer buys only one unit of the good from the firm with the lowest delivered price: The mill price plus the transportation cost. Consumers transport their purchase home at a cost $t d^{2}$, where $t$ is a positive constant and $d$ is the distance from the firm's location to the consumer's home. Each consumer derives a surplus from consumption, gross of price and transportation costs, denoted by $s$. Thus, total gross consumer surplus in each town is $s / 2$. We assume that $s$ is large enough for all consumers to buy one unit of the product each.

There are two firms indexed by $i(i=1,2)$ competing in the linear city. Let $x_{i}$ denote the location of firm $i$. Firm 1 is the local firm of town 1 and it is located within the limits of that town: $x_{1} \in[0,1 / 2]$. Firm 2 is the local firm of town 2 and it is located within the limits of that town: $x_{2} \in[1 / 2,1]$. In each town the local regulator may apply zoning restrictions that constrain the location of the local firm within the town. Thus, each town may have two different zones: an area that can be shared by consumers and the local firm and an exclusively residential area. Locations are a long-term decision which cannot therefore be changed. Firms' production costs are normalized to zero.

We assume that the ownership of firms by investors from the two towns 
is symmetric: a fraction $\alpha$ of the local firm belongs to local investors and a fraction $1-\alpha$ belongs to investors from the other town. This setting enables us to study incentives to zone on the part of the regulators that do not rely on the asymmetry in the ownership of local firms between towns; it is also required to avoid cumbersome computations.

The timing of the game is the following: In the first stage the regulators simultaneously decide whether to zone their towns or not. In the second stage, when there are zoning regulations the locations where local firms are permitted to set up are announced. In the third stage the firms simultaneously decide their locations within their towns, taking into account any zoning constraints. In stage four, the firms simultaneously set uniform prices. We solve the game by backward induction to find the subgame perfect Nash equilibria.

Let $p_{i}$ denote the price set by firm $i(i=1,2)$. The location of the consumer who is indifferent as regards buying from one firm or the other, $\bar{x}$, is obtained from the following condition:

$$
p_{1}+t\left(\bar{x}-x_{1}\right)^{2}=p_{2}+t\left(\bar{x}-x_{2}\right)^{2} .
$$

From expression (1) the following is obtained:

$$
\bar{x}=\frac{p_{2}-p_{1}}{2 t\left(x_{2}-x_{1}\right)}+\frac{x_{2}+x_{1}}{2} .
$$

Thus, the respective demands of firms 1 and 2 when they are not located at $1 / 2$, are given by $q_{1}$ and $q_{2}$ :

$$
q_{1}=\left\{\begin{array}{cc}
\bar{x} & \text { if } 0 \leq \bar{x} \leq 1 \\
1 & \text { if } \bar{x}>1 \\
0 & \text { if } \bar{x}<0
\end{array} \quad, q_{2}=\left\{\begin{array}{cc}
1-\bar{x} & \text { if } 0 \leq 1-\bar{x} \leq 1 \\
1 & \text { if } 1-\bar{x}>1 \\
0 & \text { if } 1-\bar{x}<0
\end{array}\right.\right.
$$

We proceed by backward induction, so we first solve the fourth stage of the game to obtain equilibrium prices. In this stage firms simultaneously set their prices and their outputs are then determined by expression (3). The objective 
function of firm $i$ is:

$$
\pi_{i}\left(p_{i}, p_{j}\right)=p_{i} q_{i}, i \neq j ; i, j=1,2
$$

Substituting (2) and (3) in (4) and taking the first order condition with respect to prices for each firm we obtain the equilibrium prices when both firms sell the good: ${ }^{10}$

$$
p_{1}=\frac{t}{3}\left(x_{2}-x_{1}\right)\left(2+x_{1}+x_{2}\right), p_{2}=\frac{t}{3}\left(x_{2}-x_{1}\right)\left(4-x_{1}-x_{2}\right) .
$$

From expressions (2) to (5), the profits of firms 1 and 2 are:

$$
\pi_{1}=\frac{t}{18}\left(x_{2}-x_{1}\right)\left(2+x_{1}+x_{2}\right)^{2}, \pi_{2}=\frac{t}{18}\left(x_{2}-x_{1}\right)\left(4-x_{1}-x_{2}\right)^{2} .
$$

Expressions for equilibrium prices (5), the location of the indifferent consumer (2), and firms' profits (6) can be used throughout the different scenarios analyzed in this paper. ${ }^{11}$

Each regulator's objective function $W_{i}$ is the sum of the local consumer surplus, $C S_{i}$, and the surplus of local investors. The latter comprises a fraction $\alpha$ of the profits of the local firm and a fraction $1-\alpha$ of the profits of the non-local firm:

$$
W_{i}=C S_{i}+\alpha \pi_{i}+(1-\alpha) \pi_{j}, i, j=1,2, i \neq j
$$

To obtain the objective function for each regulator, first consider that the locations and prices set by the two firms are such that $\bar{x}>1 / 2$. In that case, town 1's social welfare $\left(W_{1}\right)$ comprises the following: The gross surplus of local consumers $s / 2$, minus the price and the transportation costs paid by local consumers (who all buy from firm 1), plus a fraction $\alpha$ of the profits of firm 1 (some from its sales in town 2), plus a fraction $1-\alpha$ of the profits of firm 2 (obtained only from local consumers in town 2 ). When $\bar{x}=1 / 2$ each market

\footnotetext{
${ }^{10}$ The second order conditions of the problems that we analyze are always satisfied.

${ }^{11}$ The analysis that includes equations (1) to (6) can be found in Anderson et al. (1992, Chapter 8).
} 
is covered by the local firm and local profits are equal to consumer spending. Finally, when $\bar{x}<1 / 2$ town 1's social welfare is the following: the gross surplus $s / 2$, minus the price paid by local consumers (some buy from the local firm and others from firm 2), minus the transportation costs of local consumers (those located between 0 and $\bar{x}$ buy from firm 1 so they transport their purchase from $x_{1}$, and the rest buy from firm 2 and transport their purchase from $x_{2}$ ), plus a fraction $\alpha$ the profits of firm 1 (which only sells to local consumers), plus a fraction $1-\alpha$ of the profits of firm 2 (obtained from local consumers and others from town 1). Following similar reasoning, $W_{2}$ can be written. Equations (8) and (9) show these expressions:

$$
\begin{aligned}
& W_{1}=\left\{\begin{array}{cc}
s / 2-p_{1} / 2-\int_{0}^{1 / 2} t\left(x-x_{1}\right)^{2} d x+\alpha p_{1} \bar{x} & \text { if } \bar{x}>1 / 2 \\
+(1-\alpha)(1-\bar{x}) p_{2} & \\
s / 2-p_{1} / 2-\int_{0}^{1 / 2} t\left(x-x_{1}\right)^{2} d x+\alpha p_{1} / 2 & \text { if } \bar{x}=1 / 2 \\
+(1-\alpha) p_{2} / 2 & \\
s / 2-p_{1} \bar{x}-p_{2}(1 / 2-\bar{x})-\int_{0}^{\bar{x}} t\left(x-x_{1}\right)^{2} d x & \text { if } \bar{x}<1 / 2 \\
-\int_{\bar{x}}^{1 / 2} t\left(x-x_{2}\right)^{2} d x+p_{1} \bar{x}+(1-\alpha)(1-\bar{x}) p_{2} &
\end{array}\right. \\
& W_{2}=\left\{\begin{array}{cc}
s / 2-p_{1}(\bar{x}-1 / 2)-p_{2}(1-\bar{x})-\int_{1 / 2}^{\bar{x}} t\left(x-x_{1}\right)^{2} d x & \text { if } \bar{x}>1 / 2 \\
-\int_{\bar{x}}^{1 / 2} t\left(x-x_{2}\right)^{2} d x+\alpha(1-\bar{x}) p_{2}+(1-\alpha) p_{1} \bar{x} & \\
s / 2-p_{2} / 2-\int_{1 / 2}^{1} t\left(x-x_{2}\right)^{2} d x+\alpha p_{2} / 2 & \text { if } \bar{x}=1 / 2 \\
+(1-\alpha) p_{1} / 2 & \\
s / 2-p_{2} / 2-\int_{1 / 2}^{1} t\left(x-x_{2}\right)^{2} d x+\alpha(1-\bar{x}) p_{2} & \text { if } \bar{x}<1 / 2 \\
+(1-\alpha) p_{1} \bar{x} &
\end{array}\right.
\end{aligned}
$$

Figure 1 depicts $C S_{1}, \pi_{1}$ and $\pi_{2}$ when $\bar{x}>1 / 2$. The lined area above $p_{1}+T C_{1}$ (from $x=0$ to $x=1 / 2$ ) measures the consumer surplus in town 1 . The lined area below $p_{1}$ (from $x=0$ to $x=\bar{x}$ ) measures the profits of firm 1, although only a fraction $\alpha$ is considered from a social welfare viewpoint. Finally, the lined area below $p_{2}$ (from $x=\bar{x}$ to $x=1$ ) represents the profits of firm 2 , but only a fraction $1-\alpha$ is considered from a social welfare viewpoint in town 1 .

\section{[INSERT FIGURE 1 AROUND HERE]}


Figure 2 depicts $C S_{2}, \pi_{2}$ and $\pi_{2}$ when $\bar{x}>1 / 2$. The lined area above $p_{2}+T C_{2}$ (from $x=0$ to $x=1 / 2$ ) measures the consumer surplus in town 2. The lined area below $p_{1}$ (from $x=0$ to $x=\bar{x}$ ) measures the profits of firm 1 . Finally, the lined area below $p_{2}$ (from $x=\bar{x}$ to $x=1$ ) represents the profits of firm 2 .

\section{[INSERT FIGURE 2 AROUND HERE]}

\section{Results}

In this section we study the optimal locations and welfare from the regulators' viewpoints. We first consider the case without zoning regulations, then we describe the zoning design that achieves the optimal location of the local firm depending on the behavior of the other regulator, with zoning in both towns and in only one. Finally, we study the regulators' incentives to zone their towns or not.

\subsection{Firms' locations without zoning regulations}

Let superscript $N N$ denote that towns 1 and 2 are not zoned. Given that $\partial \pi_{1} / \partial x_{1}<0$ and $\partial \pi_{2} / \partial x_{2}>0$, when firms are free lo locate both firms locate at the end points of the linear city (i.e. $x_{1}=0$ and $x_{2}=1$ ), as shown by d'Aspremont et al. (1979). Thus, firms' locations do not depend on the value of parameter $\alpha$. It is easy to see that the profits of firm $i$, its price, and the social welfare in each town are the following:

$$
\pi_{i}^{N N}=\frac{t}{2}, p_{i}^{N N}=t, W_{i}^{N N}=\frac{s}{2}-\frac{t}{24}, i=1,2 .
$$

\subsection{Firms' locations with zoning in both towns}

Both towns are zoned, so each firm must locate in the area allowed in its town. Given that $\partial \pi_{1} / \partial x_{1}<0$ and $\partial \pi_{2} / \partial x_{2}>0$, the location that maximizes the profits of a firm for a given location of its rival is the location that maximizes the distance between the two firms while observing the zoning constraints. Firm 1 locates as close as allowed to the left border of its town $\left(x_{1}=0\right)$. Similarly, firm 2 
locates as close to the right border of its town $\left(x_{2}=1\right)$ as the zoning constraints allow. Proposition 1 describes the zoning design and shows equilibrium locations.

Proposition 1 When $\alpha \leq 3 / 8$ there are no zoning restrictions and the equilibrium locations are $x_{1}^{*}=0$ and $x_{2}^{*}=1$. When $\alpha>3 / 8$ zoning regulations forbid firm 1 to locate within the interval $[0,1 / 2-3 / 16 \alpha)$ and force firm 2 to locate outside the interval $(1 / 2+3 / 16 \alpha, 1]$. Equilibrium locations are $x_{1}^{*}=$ $1 / 2-3 / 16 \alpha$ and $x_{2}^{*}=1 / 2+3 / 16 \alpha$.

Proof. Assume without loss of generality that firm 1 is located closer to the middle of the market than firm 2, so it captures some consumers that live in town 2. In that case, from (8) we obtain that $W_{1}=s / 2-p_{1} / 2-\int_{0}^{1 / 2} t\left(x-x_{1}\right)^{2} d x+$ $\alpha \pi_{1}+(1-\alpha) \pi_{2}$. Substituting (2), (5) and (6) in this expression, maximizing with respect to $x_{1}$, and solving for $x_{1}$, the regulator's reaction function is $x_{1}\left(x_{2}\right)=$ $\left(4-2 x_{2}-24 \alpha+\sqrt{2\left(8 x_{2}^{2}-24 \alpha+48 x_{2} \alpha+288 \alpha^{2}-25-8 x_{2}\right)}\right) / 6$. Using (9), social welfare for the regulator of town 2 is $W_{2}=s / 2-p_{1}(\bar{x}-1 / 2)-p_{2}(1-\bar{x})-$ $\int_{1 / 2}^{\bar{x}} t\left(x-x_{1}\right)^{2} d x-\int_{\bar{x}}^{1 / 2} t\left(x-x_{2}\right)^{2} d x+\alpha \pi_{2}+(1-\alpha) \pi_{1}$. Substituting (2), (5) and (6) in this expression, maximizing with respect to $x_{2}$, and solving for $x_{2}$, the reaction function is $x_{2}\left(x_{1}\right)=\left(2-x_{1}+8 \alpha-2 \sqrt{x_{1}^{2}+2 \alpha-4 x_{1}+16 \alpha^{2}-2-x_{1}}\right) / 3$. Solving for the two reaction functions simultaneously gives $x_{1}^{*}=1 / 2-3 / 16 \alpha$ and $x_{2}^{*}=1 / 2+3 / 16 \alpha$. These values are valid only when $\alpha>3 / 8$, so in that case firms 1 and 2 adopt symmetric locations with regard to the border between the two towns and obtain the same market share. Due to the symmetry of the model, the same is obtained when it is assumed that it is firm 2 which can capture consumers from town 1 . When $\alpha \leq 3 / 8$ the optimal locations are $x_{1}^{*}=0$ and $x_{2}^{*}=1$.

When $\alpha>3 / 8$, firms locate optimally when the zoning regulations forbid firm 1 to locate within the interval $[0,1 / 2-3 / 16 \alpha)$ and firm 2 to locate within the interval $(1 / 2+3 / 16 \alpha, 1]$. To show that the zoning regulation works, note that, given the location of firm 2, firm 1 locates as far as possible from its rival to mitigate price competition and thus maximize profits. With the suggested 
zoning regulation, firm 1 chooses the closest location to $x=0$ that is allowed, which in this case is $x_{1}^{*}=1 / 2-3 / 16 \alpha$. From firm 2 's viewpoint the analysis is symmetrical so $x_{2}^{*}=1 / 2+3 / 16 \alpha$. When $\alpha \leq 3 / 8$, the equilibrium locations are $x_{1}^{*}=0$ and $x_{2}^{*}=1$, so zoning constraints are not required.

Proposition 1 shows that firms locate symmetrically with regard to the border between the two towns. Moreover, the left zone of town $1, x \in[0,1 / 2-3 / 16 \alpha)$, and the right zone of town $2, x \in(1 / 2+3 / 16 \alpha, 1]$, are for residential use only. The remaining zones of the towns (i.e. the central area of the linear city) may be shared by firms and consumers. In equilibrium, given that firms are located symmetrically, both firms set the same prices, sell the same output, and obtain the same profits. Note that the lower $\alpha$ is, the further apart the two firms are finally located. This is because local profits are less substantial from a social welfare viewpoint and the regulator has more incentives to increase the distance from the rival. Thus, in each town, the lower the parameter $\alpha$ is, the smaller the area exclusively for residential use is.

Let superscript ZZ denote that both towns are zoned. It is easy to compute that when $\alpha>3 / 8$ the profits of firm $i$, its price, and social welfare in each town are given by:

$$
\pi_{i}^{Z Z}=\frac{3 t}{16 \alpha}, p_{i}^{Z Z}=\frac{3 t}{8 \alpha}, W_{i}^{Z Z}=\frac{s}{2}-\frac{\left(27-72 \alpha+64 \alpha^{2}\right) t}{1536 \alpha^{2}}, i=1,2 .
$$

When $\alpha \leq 3 / 8$ the results are the same as when there are no zoning regulations because the locations are the same.

\subsection{Firms' locations with regulatory restrictions in one town only}

Now assume that only one town is zoned. It can be assumed with no loss of generality that only the regulator of town 1 restricts the location of its firm. The results when only firm 2 is zoned are symmetric. Proposition 2 shows equilibrium locations and zoning constraints.

Proposition 2 When $\alpha>3 / 8$ the zoning regulations in town 1 forbid firm

1 to locate within the interval $\left[0,\left(2-24 \alpha+\sqrt{2\left(24 \alpha+288 \alpha^{2}-25\right)}\right) / 6\right)$. Firm 
1 locates at $x_{1}^{*}=\left(2-24 \alpha+\sqrt{2\left(24 \alpha+288 \alpha^{2}-25\right)}\right) / 6$ and firm 2 locates at $x_{2}^{*}=1$. When $\alpha \leq 3 / 8$ there are no zoning restrictions and the equilibrium locations are: $x_{1}^{*}=0$ and $x_{2}^{*}=1$.

Proof. Note that although firms decide their locations simultaneously in the third stage of the game, the regulator of town 1 chooses the location restrictions in the second stage. The preceding analysis shows that in equilibrium firm 2 is located at $x_{2}=1$, since it is not subject to regulations. Thus, the result of the game is the same when $W_{1}$ is maximized subject to $x_{2}=1$ as when the reaction function of the regulator of town 1 is calculated for $x_{2}=1$. For the sake of simplicity, we use the latter approach. ${ }^{12}$

The regulator of town 1 maximizes $W_{1}$ taking into account that $x_{2}=1$. Thus, the first order condition obtained above can be used: $x_{1}\left(x_{2}\right)=(4-$ $\left.2 x_{2}-24 \alpha+\sqrt{2\left(8 x_{2}^{2}-24 \alpha+48 x_{2} \alpha+288 \alpha^{2}-25-8 x_{2}\right)}\right) / 6$, solving for $x_{2}=1$. The solution is $x_{1}^{*}=\left(2-24 \alpha+\sqrt{2\left(24 \alpha+288 \alpha^{2}-25\right)}\right) / 6$ and $x_{2}^{*}=1$ when $\alpha>3 / 8$; and $x_{1}^{*}=0$ and $x_{2}^{*}=1$ when $\alpha \leq 3 / 8$. The zoning regulation in town 1 when $\alpha>3 / 8$ guarantees that firm 1 locates at $x_{1}^{*}=(2-24 \alpha+$ $\left.\sqrt{2\left(24 \alpha+288 \alpha^{2}-25\right)}\right) / 6$ because it is not allowed to locate within the interval $\left[0,\left(2-24 \alpha+\sqrt{2\left(24 \alpha+288 \alpha^{2}-25\right)}\right) / 6\right)$, so it locates as far as allowed from firm 2 at $x_{1}^{*}$.

Given that only town 1 is zoned this regulator tries to push the local firm towards its rival to gain market share. This incentive is weakened as $\alpha$ decreases because the regulator is then more interested in the profits of the non-local firm, so it tries to avoid any reduction in those profits by increasing the distance between the local firm and its rival. Thus, in town 1 the lower the parameter $\alpha$ becomes the lower the size of the area with a residential use only is.

Superscript $Z N$ denotes that town 1 is zoned and town 2 is not. It is easy to compute the profits, outputs, and prices set by the two firms, and

\footnotetext{
${ }^{12}$ This approach is valid as long as $x_{2}=1$. When $x_{2}$ depends on $x_{1}$ this way of finding the solution is not valid as one has to proceed backwards.
} 
the social welfare of each town for the $Z N$ case. The expressions are cumbersome, so we present the social welfare computations required to analyze the regulators' decisions as to whether or not to zone their towns. Let $\beta=$ $\sqrt{50+48 \alpha+576 \alpha^{2}}$. Thus:

$$
\begin{aligned}
& W_{1}^{Z N}=\frac{s}{2}+\frac{t\left(-13824 \alpha^{3}+576 \alpha^{2}(\beta-3)+24 \alpha(87+2 \beta)-5(47+10 \beta)\right)}{1944} \\
& W_{2}^{Z N}=\frac{s}{2}-\frac{t\left(998+55296 \alpha^{3}+67 \beta-576 \alpha^{2}(29+4 \beta)+24 \alpha(33 \beta-211)\right)}{1296} .
\end{aligned}
$$

To simplify the presentation let $\gamma=\frac{-13824 \alpha^{3}+576 \alpha^{2}(\beta-3)+24 \alpha(87+2 \beta)-5(47+10 \beta)}{1944}$ and $\delta=-\frac{998+55296 \alpha^{3}+67 \beta-576 \alpha^{2}(29+4 \beta)+24 \alpha(33 \beta-211)}{1296}$. Thus, expressions for social welfare can be rewritten as follows:

$$
W_{1}^{Z N}=\frac{s}{2}+t \gamma, W_{2}^{Z N}=\frac{s}{2}+t \delta
$$

\subsection{To zone or not to zone: The regulators' choices}

Above we solved the fourth and third stages of the game taking into account the optimal location restrictions enforced by the regulators. We now study whether the regulators have incentives to zone their towns or not. Table 1 shows the social welfare obtained by the two towns when $\alpha>3 / 8$, depending on whether their regulators zone each town or not. The case when $\alpha \leq 3 / 8$ is of little interest since the social welfare maximizing locations are met without zoning.

\section{[INSERT TABLE 1 AROUND HERE]}

Next we show the different equilibria configurations in the first stage of the game.

Proposition 3 When $\alpha>0.4765$ both towns are zoned. When $3 / 8<\alpha \leq$ 0.4765 only one regulator zones its town. When $\alpha \leq 3 / 8$ all four equilibrium 
configurations are possible: Both regulators refuse to zone, both zone their towns, and only one regulator zones.

Proof. The case when $\alpha \leq 3 / 8$ is standard because firms are always located at the endpoints of the segment $[0,1]$, so the results do not depend on the zoning constraints. Thus, we have four equilibria: both regulators refuse to zone, both of them zone, and only one regulator zones.

When $\alpha>3 / 8$ we find that $W_{1}^{Z Z}-W_{1}^{N Z}=$

$-\frac{t\left(729-1944 \alpha+1769472 \alpha^{5}-18432 \alpha^{4}(29+4 \beta)+768 \alpha^{3}(33 \beta-211)+32 \alpha^{2}(1052+67 \beta)\right)}{41472 \alpha^{2}}>0$ if and only if $\alpha>0,4765$; and $W_{1}^{Z N}-W_{1}^{N N}=\frac{t\left(-77-6912 \alpha^{3}-25 \beta+288 \alpha^{2}(\beta-3)+12 \alpha(87+2 \beta)\right)}{972}>$ 0 if and only if $\alpha \geq 3 / 8$. For town 2 the results are symmetric. As a result, when $3 / 8<\alpha \leq 0.4765$ only one regulator zones. When $\alpha>0.4765$ both towns are zoned because zoning is a dominant strategy for both regulators.

It is easy to check that when only one town is zoned, and zoning regulations constrain the location of the local firm the town without zoning obtains higher social welfare. ${ }^{13}$ This is because zoning constraints increase the profits of the local firm but when $\alpha$ is low $(3 / 8<\alpha \leq 0.4765)$ the profits of the firm located in the other market are more important for the local regulator than the profits of the local firm.

\section{Conclusions}

Zoning regulations may help local authorities to achieve social welfare goals. Regulators take into account local consumers' transportation costs and local and foreign profits, so local authorities may use zoning strategically. Without zoning regulations firms locate far from their rivals to mitigate price competition, so zoning can be used to push firms into locating closer to the rivals.

The existence of equally shared ownership of firms in two neighboring towns affects the optimal design of zoning in both towns and the regulators' incentives to zone each town or not. When the weight of local profits in social welfare

\footnotetext{
${ }^{13}$ Comparing $W_{1}^{Z N}$ and $W_{2}^{Z N}$ for $3 / 8<\alpha \leq 0.4765$ we obtain that $W_{1}^{Z N}<W_{2}^{Z N}$ because $\delta>\gamma$.
} 
is high enough compared to foreign profits, both towns are zoned and zoning constraints are intense. Thus, the higher this weight is the closer together firms are encouraged to locate because zoning regulations push the local firm towards its rival.

When local profits are of intermediate significance an asymmetric result emerges: only one town is zoned, despite the symmetry in the weight of local and foreign profits in the local welfare of both towns. This is because foreign profits are now more important, so it is not so attractive to zone the town when the rival does so: In that case, competition would be very fierce, which damages the profits obtained by the firm in the other town. As a result, when the equilibrium involves zoning in one town only, the town that is not zoned obtains higher social welfare than its rival because foreign profits are greater than local ones.

Finally, when the weight of local profits in social welfare is very low both regulators have incentives to locate their firms very far from their rival to avoid damaging the profits obtained in the other town. The regulators' incentives and the incentives of the firms are then not in conflict, so zoning is not necessary.

Acknowledgements Financial support from Ministerio de Ciencia y Tecnología (ECO2015-66803-P) and the University of the Basque Country, UPV/EHU (GIU17/051) is gratefully acknowledged.

\section{References}

Anderson SP, de Palma A, Thisse J-F (1992) Discrete Choice Theory of Product Differentiation. M.I.T. Press, Cambridge, Massachusetts.

Bárcena-Ruiz JC, Garzón MB (2005a) Economic integration and privatization under diseconomies of scale. Eur J Polit Econ 21: 247-267.

Bárcena-Ruiz JC, Garzón MB (2005b) International trade and strategic privatization. Rev Develop Econ 9: 502-513. 
Bárcena-Ruiz JC, Casado-Izaga FJ (2014) Zoning under spatial price discrimination. Econ Inquiry 52: 659-665.

Bárcena-Ruiz JC, Casado-Izaga FJ (2016) Foreign-owned firms and zoning under spatial price discrimination. Lett Spat Res Sci 9: 145-155.

Bárcena-Ruiz JC, Casado-Izaga FJ (2017) Zoning a cross-border city. J Reg Sci 57: 173-189

Bárcena-Ruiz JC, Casado-Izaga FJ (2018) Zoning a metropolitan area. Pap Reg Sci 97: S123-S137.

Bárcena-Ruiz JC, Casado-Izaga FJ, Hamoudi H (2014) Optimal zoning of a mixed duopoly. Ann Reg Sci 52: 141-153.

Bárcena-Ruiz JC, Casado-Izaga FJ, Hamoudi H, Rodríguez I (2016) Optimal zoning in the unconstrained Hotelling game. Pap Reg Sci 95: 427-435.

Boarnet MG, Crane R. (1998) Public finance and transit-orientated planning: new evidence from Southern California. J Plann Educ Res 17: 206-219.

Braid RM (1993) Spatial competition between jurisdictions which tax perfectly competitive retail (or production) centers. J Urban Econ 34: 75-95.

Braid RM (2000) A spatial model of tax competition with multiple tax instruments. J Urban Econ 47: 88-114.

Cato S, Matsumura T (2017) Optimal production tax and privatization policies under an endogenous market structure. MPRA Paper No. 82893, posted 23 November 2017 16:17 UTC. https://mpra.ub.uni-muenchen.de/82893/. Accessed 28th. June, 2018.

Chen CS, Lai FC (2008) Location choice and optimal zoning under Cournot competition. Reg Sci Urban Econ 38: 119-126.

Colombo S (2012) On optimal zoning in a linear town with Cournot competitors. Lett Spat Res Sci 5: 113-118.

Corneo G, Jeanne O (1994) Oligopole mixte dans un marche commun. Annales d'Economie et de Statistique 33: 73-90.

d'Aspremont C, Gabszewicz JJ, Thisse J-F (1979) On Hotelling's stability 
in competition. Economet 47: 1145-1150.

Fjell K, Pal D (1996) A mixed oligopoly in the presence of foreign private firms. Can J Econ 29: 737-743.

Hamoudi H, Risueño M (2012) The effects of zoning in spatial competition. J Reg Sci 52: 361-74.

Hanssen J U, Foslt O (1998) Shopping malls-location and use. A study of ski and vinterbro shopping malls focusing on the users and their transport. TØI report 394/1998. Available at

https://www.toi.no/getfile.php/Publikasjoner/T\%C3\%98I\%20rapporter/1998/3941998/sum-394-98.pdf

Heim CE (2012) Border wars: Tax revenues, annexation, and urban growth in Phoenix. Int $J$ Urban Reg Res 36: 831-859.

Henninger G (2015) How municipal finance creates regional shopping centers. Available at http://www.fromsuburbia.com/2015/01/how-municipal-finance-createsregional-shopping-centers/

Heywood JS, Ye G (2009) Mixed oligopoly and spatial price discrimination with foreign firms. Reg Sci Urban Econ 39, 592-601.

Hrelja R, Karolina I, Richardson T (2012) IKEA and small city development in Sweden: Planning myths, realities, and unsustainable mobilities. Int Plann Stud 17: 125-145.

Hotelling H (1929) Stability in competition. Econ J 39: 41-57.

Inoue T, Kamijo Y, Tomaru Y (2009) Interregional mixed duopoly. Reg Sci Urban Econ 39: 233-242.

Lai FC, Tsai JF (2004) Duopoly locations and optimal zoning in a small open city. J Urban Econ 55: 614-626.

Lin MH, Matsumura T (2012) Presence of foreign investors in privatized firms and privatization policy. $J$ Econ 107: 71-80.

Löfgren O (2008) Regionauts: The transformation of cross-border regions in Scandinavia. Eur Urban Reg Stud 15: 195-209. 
Lorentzon, S (2011) Shopping along the border between Norway and Sweden as engine of regional development. Occasional Papers 2011:4. Available at http://www.ipd.gu.se/digitalAssets/1349/1349301_occ-p-20114.pdf

Matsumura T, Matsushima N (2012) Locating outside a linear city can benefit consumers. J Reg Sci 52: 420-432.

Matsumura T, Matsushima N, Ishibashi I (2009) Privatization and entries of foreign enterprises in a differentiated industry. J Econ 98: 203-219.

Matsushima N, Matsumura T (2006) Mixed oligopoly, foreign firms and location choice. Reg Sci Urban Econ 36: 753-772.

Pal D, White MD (1998) Mixed oligopoly, privatization, and strategic trade policy. Southern Econ J 65: 264-281.

Salcedo R (2003) When the global meets the local at the mall. Am Behav Sci 46: 1084-1103.

Spierings B, van der Velde M (2013) Cross-border differences and unfamiliarity: Shopping mobility in the Dutch-German Rhine-Waal Euroregion. Eur Plann Stud 21: 5- 23.

Sullivan P, Bonn MA, Bhardwaj V, DuPont A (2012) Mexican national cross-border shopping: Exploration of retail tourism. J Retailing Consum Serv 19: 596-604.

Suzuki J (2013) Land use regulations as a barrier to entry: Evidence from the Texas lodging industry. Int Econ Rev 54: 495-523.

Timothy DJ, Butler RW (2005) Cross-border shopping: Canada and the United States, In P. Ganster and D. E, Lorey (eds.), Borders and Border Politics in Globalizing World. S.R. Books, Laham-Boulder-New York-Toronto-Oxford, 285-300. 


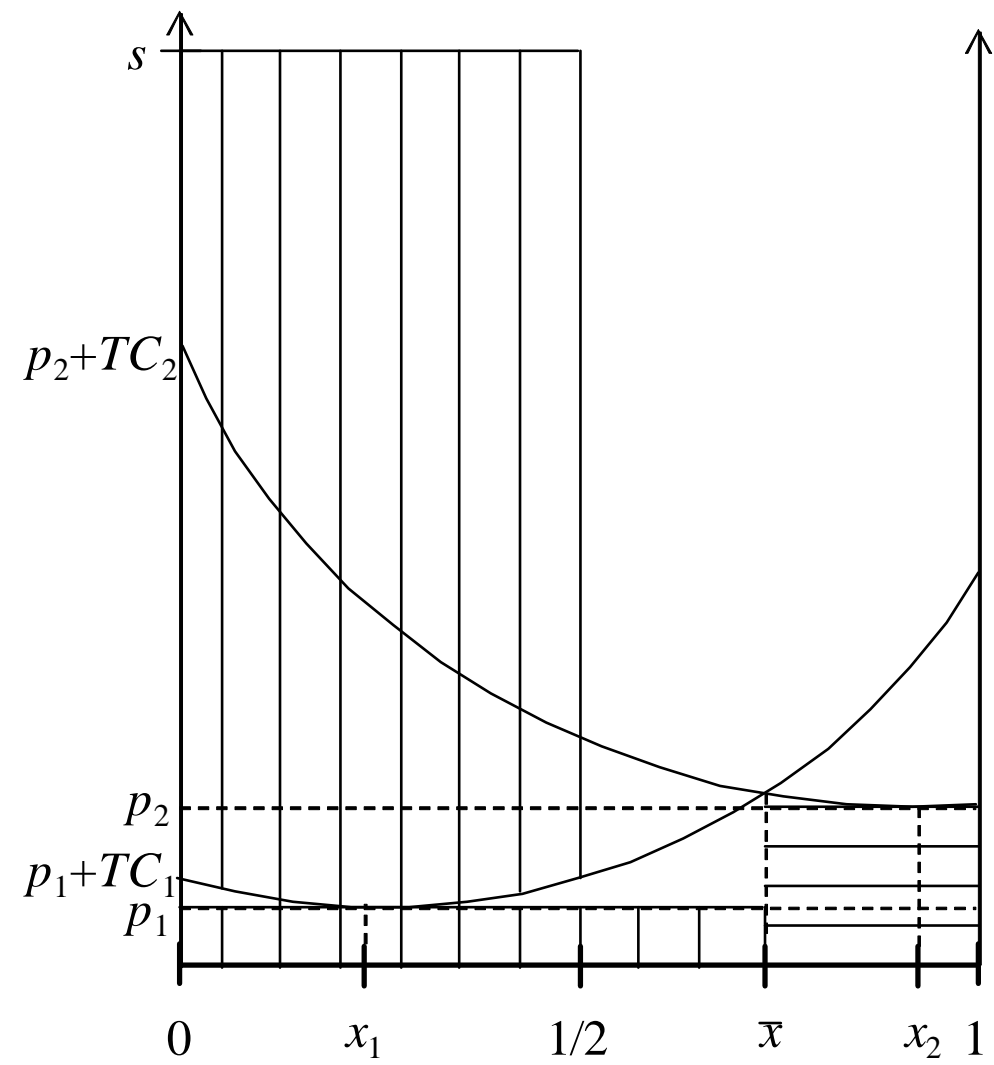

Fig. 1 Consumers' surplus in town 1 and firms' profits when $\bar{x}>1 / 2$. 


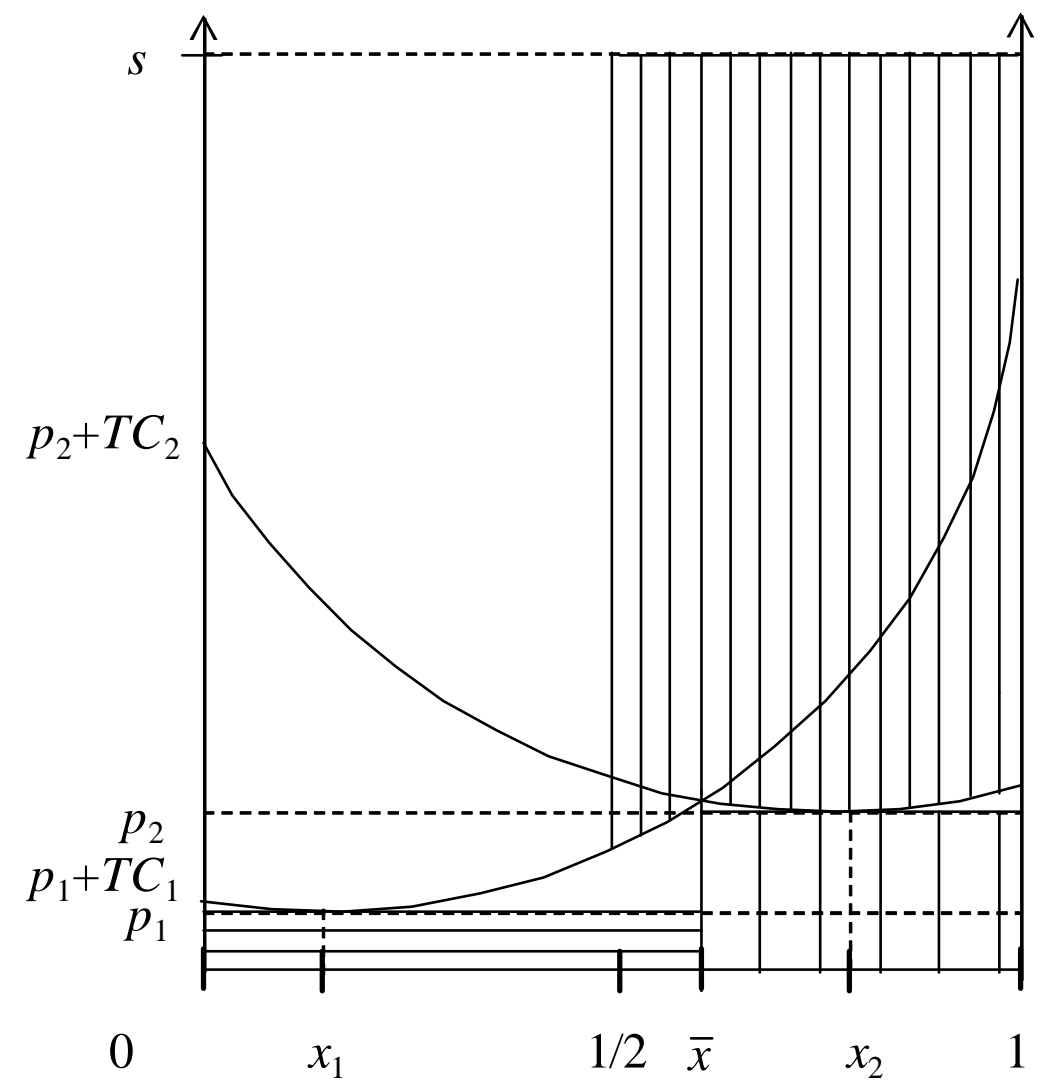

Fig. 2 Consumers' surplus in town 2 and firms' profits when $\bar{x}>1 / 2$. 
Table 1. Payoff matrix in the first stage of the game for $\alpha>3 / 8$.

\begin{tabular}{|c|c|c|}
\hline Town $1 \backslash 2$ & $Z$ & $N$ \\
\hline$Z$ & $\begin{aligned} & \frac{s}{2}-\frac{\left(27-72 \alpha+64 \alpha^{2}\right) t}{1536 \alpha^{2}} \\
& \frac{s}{2}-\frac{\left(27-72 \alpha+64 \alpha^{2}\right) t}{1536 \alpha^{2}}\end{aligned}$ & $\frac{s}{2}+t \gamma$ \\
\hline$N$ & $\begin{array}{l}\frac{s}{2}+t \delta \\
\quad \frac{s}{2}+t \gamma\end{array}$ & $\frac{s}{2}-\frac{t}{24}$ \\
\hline
\end{tabular}

